Abstracta Iranica Abstanica

Revue bibliographique pour le domaine irano-aryen

Volume 34-35-36 | 2017

Comptes rendus des publications de 2011-2013

\title{
Bertille Lyonnet. Questions on the Date of the Hellenistic Pottery from Central Asia (Ai Khanoum, Marakanda and Koktepe)
}

Johanna Lhuillier

\section{(2) OpenEdition \\ Journals}

Édition électronique

URL : http://journals.openedition.org/abstractairanica/42042

DOI : $10.4000 /$ abstractairanica.42042

ISSN : 1961-960X

Éditeur :

CNRS (UMR 7528 Mondes iraniens et indiens), Éditions de l'IFRI

Référence électronique

Johanna Lhuillier, «Bertille Lyonnet. Questions on the Date of the Hellenistic Pottery from Central Asia (Ai Khanoum, Marakanda and Koktepe) », Abstracta Iranica [En ligne], Volume 34-35-36 | 2017, document 6, mis en ligne le 30 juillet 2017, consulté le 03 octobre 2020. URL : http://journals.openedition.org/ abstractairanica/42042 ; DOI : https://doi.org/10.4000/abstractairanica.42042

Ce document a été généré automatiquement le 3 octobre 2020.

Tous droits réservés 


\section{Bertille Lyonnet. Questions on the Date of the Hellenistic Pottery from Central Asia (Ai Khanoum, Marakanda and Koktepe)}

Johanna Lhuillier

\section{RÉFÉRENCE}

Bertille Lyonnet. «Questions on the Date of the Hellenistic Pottery from Central Asia (Ai Khanoum, Marakanda and Koktepe) ». Ancient Civilizations from Scythia to Siberia, 18, 2012, p. 143-173.

1 Cet article offre une version actualisée d'un article publié par l'A. en français dans un ouvrage édité en Ouzbékistan (« D’Aï Khanoum à Koktepe. Questions sur la datation absolue de la céramique hellénistique d'Asie centralE ", in : K. Abdullaev, ed., The traditions of East and West in the Antique cultures of Central Asia, Papers in Honor of Paul Bernard. Samarkand-Tashkent, 2010.). Il dresse un parallèle entre les assemblages céramiques des niveaux hellénistiques de trois sites dont l'A. a une connaissance directe afin d'en préciser la datation : Aï Khanoum en Afghanistan (Bactriane), Afrasiab (Marakanda) et Koktepe en Ouzbékistan (Sogdiane). Pour chaque site, l'A. reprend les anciennes hypothèses, les confronte aux données les plus récentes, portant notamment sur la datation d'un certain nombre de types céramiques considérés comme des marqueurs chronologiques fiables, et les met en parallèle avec les données numismatiques récentes. Le texte est illustré de planches synthétiques de céramique d'Aï Khanoum et d'Afrasiab.

2 L'A. conclut qu'Aï Khanoum, en tout cas la ville basse, a probablement été fondée sous le règne d'Antiochos $\mathrm{I}^{\mathrm{er}}$. La période suivant son règne est en revanche caractérisée en 
Sogdiane par un affaiblissement du pouvoir grec, tandis que la céramique datant de la phase de la conquête ne diffère pas nettement de celle des niveaux achéménides.

\section{AUTEURS}

\section{JOHANNA LHUILLIER}

UMR 5133 CNRS-Université de Lyon 